\title{
Designing a paediatric hospital information tool with children, parents, and healthcare staff: a UX study
}

Lisa Aufegger º, Khánh Hà Bùi, Colin Bicknell and Ara Darzi

\begin{abstract}
Background: The hospital patient pathway for having treatment procedures can be daunting for younger patients and their family members, especially when they are about to undergo a complex intervention. Opportunities to mentally prepare young patients for their hospital treatments, e.g. for surgical procedures, include tools such as therapeutic clowns, medical dolls, or books and board games. However, while promising in reducing pre-operative anxiety and negative behaviours, they may be resource intensive, costly, and not always readily available. In this study, we co-designed a digital hospital information system with children, parents and clinicians, in order to prepare children undergoing medical treatment.
\end{abstract}

Method: The study took place in the UK and consisted of two parts: In part 1, we purposively sampled 37 participants ( $n=22$ parents, and $n=15$ clinicians) to understand perceptions and concerns of an hospital information platform specifically design for and addressed to children. In part 2, 14 children and 11 parents attended an audio and video recorded co-design workshop alongside a graphic designer and the research team to have their ideas explored and reflected on for the design of such information technology. Consequently, we used collected data to conduct thematic analysis and narrative synthesis.

Results: Findings from the survey were categorised into four themes: (1) the prospect of a hospital information system (parents' inputs); (2) content-specific information needed for the information system (parents' and clinicians' inputs); (3) using the virtual information system to connect young patients and parents (parents' inputs); and (4) how to use the virtual hospital information system from a clinician's perspective (clinicians' inputs). In contrast, the workshop highlighted points in times children were most distressed/relaxed, and derived the ideal hospital visit in both their and their parents' perspectives.

Conclusions: The findings support the use of virtual information systems for children, in particular to explore and learn about the hospital, its facilities, and the responsibilities of healthcare professionals. Our findings call for further investigations and experiments in developing safer and more adequate delivery of care for specific age groups of healthcare users. Practical and theoretical implications for improving the quality and safety in healthcare delivery are discussed.

Keywords: Children hospital information system, User experience design, Patient and public engagement

* Correspondence: l.aufegger@imperial.ac.uk

(NIHR) Imperial Patient Safety Translation Research Centre (PSTRC), Imperial

College London, 10 S Wharf Rd, London W2 1PE, UK

(c) The Author(s). 2020 Open Access This article is licensed under a Creative Commons Attribution 4.0 International License, which permits use, sharing, adaptation, distribution and reproduction in any medium or format, as long as you give appropriate credit to the original author(s) and the source, provide a link to the Creative Commons licence, and indicate if changes were made. The images or other third party material in this article are included in the article's Creative Commons licence, unless indicated otherwise in a credit line to the material. If material is not included in the article's Creative Commons licence and your intended use is not permitted by statutory regulation or exceeds the permitted use, you will need to obtain permission directly from the copyright holder. To view a copy of this licence, visit http://creativecommons.org/licenses/by/4.0/. The Creative Commons Public Domain Dedication waiver (http://creativecommons.org/publicdomain/zero/1.0/) applies to the data made available in this article, unless otherwise stated in a credit line to the data. 


\section{Introduction}

The hospital patient pathway for having treatment procedures can be daunting for younger patients and their family members, especially when they are about to undergo a complex intervention. Children are faced with an unfamiliar environment and daily treatment routine such as long bed days, separation from friends and loved ones and having to interact with unfamiliar healthcare professionals [1]. This can negatively impact their behaviour and emotions [2], and could lead to a slower rate of physical and emotional recovery without appropriate coping strategies from their caregivers [3-5].

One way to prepare young patients for the stress levels experienced during a hospital stay are educational initiatives and interventions [6]. These interventions are aimed at improving patients' understanding, perception and awareness around key concepts in the healthcare service and delivery process [7]. They encompass knowledge on treatment procedures, how to manage chronic diseases, and preventative initiatives explaining health risk factors and their consequences [8]. Their main goals are to enable patients to play a more active, autonomous, and informed role in their treatment process, ultimately targeting stress and anxiety reduction, improving confidence, attitude and patient satisfaction [9].

Existing healthcare designs on relieving anxiety in children have focused on therapeutic play interventions prior to and during hospitalisations and/or surgical procedures $[6,7,10-15]$. Depending on the age and cognitive development of the patient, they involve preparation plays, medical plays, distraction plays, and development plays. These focus on increasing children's understanding of medical procedures; facilitating expression of their feelings and emotions related to hospitalization; and promoting psychosocial development and preventing regression among hospitalized children. To illustrate, medical dolls have the means to explain a medical procedure [11], while videos and virtual reality games act as a distraction prior to a procedure [7]. With the support of parents and healthcare professionals, these interventions have shown to be successful in helping young patients cope with the hospital experience [4]. However, these tools have limited benefits in preparing patients for the change in environment as they take place once the child has already been admitted to hospital.

A potential approach that provides realistic expectations and understanding of the nature of a hospital admissions and treatment processes is the usage of digital application technologies. Digital health includes integrated, sustainable and patient-centred services that allow for sharing and retrieving healthcare information, and promoting effective communication between patients and healthcare providers [16].
Recent studies in paediatric treatment and care have shown that digital technology applications, such as virtual reality exposure to elective surgery procedures as part of a preparatory routine can reduce children's anxiety, stress, and postoperative maladaptive behaviours, including difficulties in getting to sleep, temper tantrum, or decreased appetite after surgery. These application have been demonstrated more impactful than standard care alone [17-19], and, in doing so, can make healthcare safer, more accessible, and cost-effective [20].

However, for patient-centred health information technologies to be truly meaningful, the user needs to be actively involved in the design process when creating such technology [21]. User-centred design (UCD) uses rigorous methods and iterative development processes, which allows researchers and developers to (1) explore and validate new opportunities to inform their vision on the technology; and (2) give quality to and optimize the design to support its usability [22]. UCD utilises different methods [23], such as observations, personas, interviews, surveys, stakeholder workshops, user journeys and/or similar. Supported by these methods, UCD seeks to ensure effectiveness, efficiency, and user satisfaction, and avoids cost-intensive changes and modifications following the technology development.

\section{Context}

Building on current UCD frameworks [21], this study aims to explore the possibility of designing a virtual information system specifically designed for and addressed to young patients, their caregivers and healthcare professionals, in order to comprehensively equip them for the hospital admission and treatment process. Specifically, this study consists of two parts: In part 1, we explored the possibility of a virtual information system to enable parents to verbally and emotionally prepare their child and themselves for their child's hospital stay. We also collected data on healthcare professionals' perceptions of such an information system, and the extent to which it is of value to healthcare service and delivery. In part 2 , we worked with children and parents to understand how the information technology can be designed, presented and delivered in an engaging, age-appropriate manner. Specifically, our overarching research questions were:

1) Part 1: What are parents' and healthcare professionals' perceptions of having a hospital information platform specifically designed for and addressed to children?

a. What are their concerns?

b. What do they think may be the benefits?

c. What content would they like the child to learn about? 
2) Part 2: What do children wish to be informed about when being prepared for a hospital admission?

a. In previous admissions, what made them feel anxious?

b. In previous admissions, what made them feel relaxed?

Information was obtained through (1) a purposive sampled group of parents and paediatric healthcare professionals, asking them about their perceptions and concerns of having a hospital information platform specifically designed for and addressed to children; and (2) a UCD workshop, where children and parents, alongside a UX designer and the research team, reflected on children's perceptions and opinions on a virtual hospital environment, and to create first frameworks on how such environment could look like.

\section{METHODS}

\section{Sample}

In part 1, a survey was sent to a total of 37 participants $(\mathrm{n}=22$ parents and 15 clinicians [nurses and consultants]) who were asked about their perceptions of having a hospital information system specifically designed for children/patients. Questions in the survey were specifically developed for this study (cf. Table 1). Based on existing recommendations [24, 25], between 10 and 15 interviews were conducted to capture meaningful information patterns within interviewees' experiences [24]. Furthermore, we assessed the data throughout the collection process to be able to determine when data saturation was reached (i.e. data does not add new meaning). The data collection took place over a period of one month, between November and December 2019. The sample was identified via purposeful outreach activities and with support of a medical student working on the paediatric ward at Imperial College NHS Trust, London. This was achieved by, for instance, approaching consultants and parents to take part in the study, and by sending out emails and posting the link of the survey on social media platforms. Written and fully informed consent was obtained before survey completion. The selection criteria for parents consisted of having experience of the hospital admission and treatment procedure for at least one child in the past. The duration of the hospital admission was flexible and could range from a few hours to a few weeks or months. For clinicians, criteria included pervious and current work experience as clinician in the paediatric healthcare sector.

In part 2, 14 children and 11 parents took part in a 2hour workshop with the aim to explore and create a virtual environment for children to learn about the hospital, facilities, and responsibilities of healthcare professionals. Inclusion criteria were children, between 8 and 10 years of age, who had experiences with hospital admission and treatment processes (irrespective of the health condition). This age group was chosen in line

Table 1 Questions used to explore parents' and healthcare professionals' thoughts and perceptions on a virtual children information system

Questions for parents
In your opinion, what kind of information and instructions should the
hospital staffs give to prepare you and your child for his/her hospital
stay?
We are interested in developing an interactive information platform in
the form of a virtual hospital for kids to explore and understand the
hospital environment. The platform would give educational quizzes and
tasks for children to learn about the hospital facilities, and jobs of doctors,
nurses and other staffs.
a. Would you have your child use this platform?
b. Where do you see the benefits? Where do you have concerns?

To what extent do you think young patients' online presence within this information platform should be monitored (for instance, children talking to each other as part of their activity)?

*Note: we would ensure no personal data could be shared and/or exploited

Within this platform, how do you feel about connecting with other parents, in order to potentially enable to exchange thoughts, advices, and to be part of a larger support group who share the same experiences.

a. Where do you see the benefits?

b. Where do you have concerns?

*Note: Personal experiences and stories would not be disclosed through

the setup of your account or registration for this game.

\section{Questions for healthcare professionals}

In your opinion, what kind of information and instructions would you, as a healthcare professional, need to give to a young patient to prepare for his/her hospital stay?

We are interested in developing an interactive information platform in the form of a virtual hospital for kids to explore and understand the hospital environment. The platform would give educational quizzes and tasks for children to learn about the hospital facilities, and jobs of doctors, nurses and other staffs.

a. What aspects of your role and the hospital environment would you like the young patients to learn about?

b. Where do you see the benefits? Where do you have concerns?

As part of the information system, how do you feel about video tutorials from healthcare professionals that advice parents on how to communicate and prepare their child for the hospital stay. Which aspects from your experience do you feel parents need most advice from healthcare professionals?

Do you have any other comments? 
with their appropriate psychological development to provide insightful inputs on their hospital experiences whilst having pragmatic contributions to the idea of using a virtual information system to explore the hospital environment [26]. The workshop was conducted at official Imperial College London White City Invention Room, and in collaboration with the Imperial College London outreach team, who recruited participants through their various collaborations with residencies from the White City area. For the workshop, parents received $£ 40$ for their and their children's participation.

The study was approved by the Imperial College Research Ethics Committee (19IC5541). Written and fully informed consent was obtained from all participants, including parents/guardians of the minors as well as the children themselves.

\section{Procedure}

In part 1 , we explored perceptions of having a hospital information system specifically designed for and addressed to children/ young patients, as well as where parents and healthcare professionals would like more guidance in informing and preparing children for the hospital admission and treatment. Table 1 shows the questions that we used in order to obtain information (cf. Table 1).

\section{Workshop}

In part 2, a workshop was designed based on a UCD framework that consisted of two activities:

\section{Activity 1}

Divided into three parts, Activity 1 aimed to create a user journey or journey mapping [27]. Journey mapping is a way to obtain the steps that are involved in a particular procedure, which, in this case, is the experience of a hospital admission and treatment [28]. In particular, we explored the temporal aspect to the admission and episode of care (i.e. medical timeline), the events that occurred in the episode of care (i.e. medical pathway), as well as goals, constraints, and healthcare professionals that were associated with and involved in the episode of care. In Activity 1a, participants were asked to create and discuss an objective description of a hospital visit and how they felt at that particular time. We plotted a framework of events to be referenced by the participants as a starting point for discussion. In Activity $1 \mathrm{~b}$, participants created a timeline with the key events during a visit to a hospital, i.e. when they encountered a problem or when they were confused or stressed. We aimed to understand the aspects of the hospital visit that could be improved from the patients' point of view. In Activity 1c, participants were asked to recall the points in time when they were most relaxed. We aimed to understand the aspects of the hospital visit that were effective and efficient for the patients.

\section{Activity 2}

In Activity 2, participants were given the opportunity to re-design their hospital visit and to consider what features they would like in a hospital visit. Here, we applied the approach of Cooperative Inquiry [29-31], to engage children in the design of new technologies, whilst also accounting for the intergenerational cooperation and partnership between adults and children [31]. Merged with participating design and human factors experts, this approach provides valuable insight that can be incorporated into a technology-based design. Using the user journey of events created in Activity $1 a-c$ and a guideline, the children and their parents were asked to think of interventions and technology-based designs that would have improved their experience. For this, the participants were divided into three groups, and each group presented their ideas and initiated open discussions from the room. The workshop was observed, and audio and video recorded by two members of the research team.

\section{Data Treatment and Analysis}

The workshop was audio recorded and transcribed by an external company. Findings from both part 1 and part 2 were documented and analysed thematically by two members of the research team. Thematic analysis is a type of qualitative research method used for identifying, analysing and reporting patterns or themes within data from an inductive, semantic, iterative approach (cf. Braun \& Clarke for a detailed overview) [32-34]. In other words, it allows to work data-driven and to provide an in-depth analysis of the patterns found within and across participants. In this study, we identified patterns within the data using an inductive 'bottom up 'approach, which is characterised by a strong link with the data, and that is absent of any aim to support a pre-existing framework or that is based on the researchers' preconceptions. This included reading the data several times in order to get familiar with the depth and breadth of the content [35]. Next, a set of initial lists of codes from the data that appeared meaningful to the first and second author. With a clear sense of the context, the coding process enabled to organise the data into themes. Themes and codes were discussed between the first and second author throughout the data analysis. After further refinement, the data was organised with accompanying narrative and supported by quotes from participants that capture the essence of the point being demonstrated. For part 1, the analytic narrative was done in consideration of perceptions and attitudes towards a virtual information system designed for and addressed to children. Similarly, for part 2, the data was analysed thematically and 
synthesised narratively with the findings of the drawings from activity 1 , where the data was coded according to the ways in which imagination was depicted in the drawings, and then assessed for content such as the key features of the children's most distressing and relaxing hospital experiences.

\section{Results}

\section{Part 1}

Findings from parents and clinicians were categorised into four themes (cf. Figs. 1 and 2): (1) The prospect of a hospital information system; (2) content-specific information needed for the information system; (3) using the virtual information system to connect young patients and parents; and (4) how to use the virtual hospital information system from a clinician's perspective.

\section{(1)The prospect of a hospital information system for} children (parents)

Parents were positive towards a hospital information system specifically designed for children. They acknowledged that providing age-appropriate medical knowledge and information about the hospital admission would increase their confidence, reduce stress, anxiety and fear of the unknown and bridge the patient-doctor power gap. They also emphasised that it would help children spend their waiting time more pleasantly while teaching them about the hospital in an engaging, non-threatening manner.

(2)Content-specific information needed for the information system (parents $\mathcal{E}$ clinicians)
Parents acknowledged the need for children to know about the hospital environment, and the roles and responsibilities of healthcare staff. Emphasis was put on information related to personal preparation at point of entry to hospital admission, i.e. whether they can stay over-night, whether they can bring personal items, what is needed, and whether and what facilities are available for them. Furthermore, they wished for an estimated timeline as to how long the admission or treatment will take, and to have information available in relation to the treatment process. Lastly, they highlighted the need for medical information that is both easily understandable for parents and conveyable to their children.

Clinicians were keen to have an information system in place that allows patients to know about eating and sleeping arrangements, the key roles and responsibilities of staff, which staff parents and young patients can talk to if they have any questions or concerns, an introduction to the physical environment, and also an estimated timeline of how long patients will be staying to receive their particular treatment. They also felt that there was a need for advising parents on what to expect during the hospital stay, especially after discharge and for potential follow-up visits.

(3) Using the virtual information system to connect children and parents (parents)

Parents expressed concerns in relation to the possibility of online communications between young patients without any external monitoring and stressed that any online activity of their children should be subject to

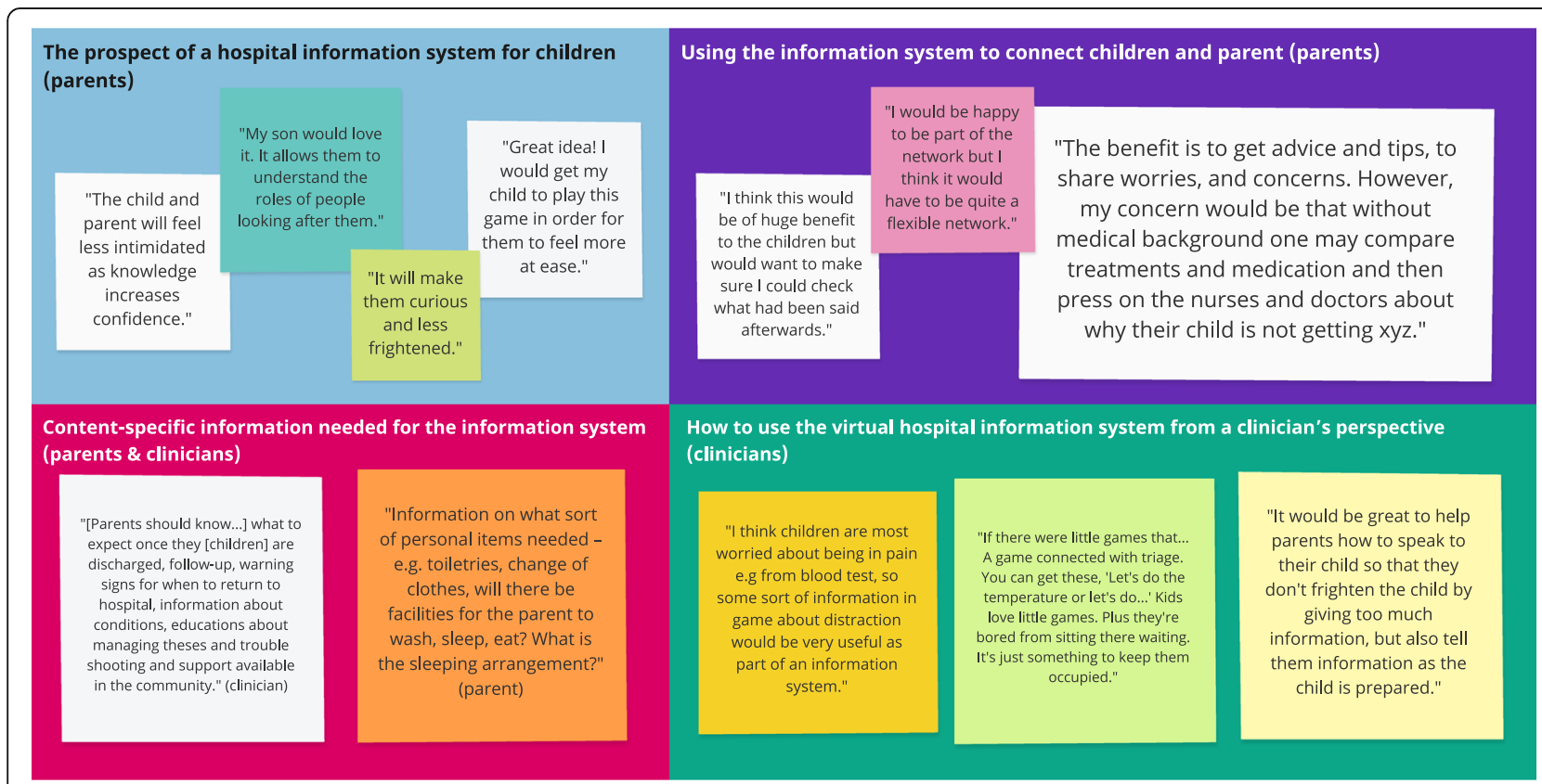

Fig. 1 Themes and exemplar quotes from the survey of both parents and clinicians (created in Miro) 


\begin{tabular}{|c|c|c|c|}
\hline $\begin{array}{l}\text { The prospect of a } \\
\text { hospital information } \\
\text { system for children }\end{array}$ & $\begin{array}{c}\text { Content-specific } \\
\text { information needed } \\
\text { for the information } \\
\text { system }\end{array}$ & $\begin{array}{l}\text { Using the virtual } \\
\text { information system } \\
\text { to connect children } \\
\text { and parents }\end{array}$ & $\begin{array}{l}\text { How to use the virtual } \\
\text { hospital information } \\
\text { system from a } \\
\text { clinician's perspective }\end{array}$ \\
\hline $\begin{array}{l}\text { - Providing age-appropriate } \\
\text { medical knowledge } \\
\text { - Increasing confidence } \\
\text { - Reducing stress and } \\
\text { anxiety } \\
\text { - Bridging patient-doctor } \\
\text { gap } \\
\text { - Distracting from treatment } \\
\text { - Helping to pass time }\end{array}$ & $\begin{array}{l}\text { - Details on the hospital } \\
\text { environment, and } \\
\text { healthcare staff's roles and } \\
\text { responsibilities } \\
\text { - Personal preparation } \\
\text { (e.g. food and sleep regime) } \\
\text { - Feedback on estimated } \\
\text { treatment duration } \\
\text { - Contact person to ask } \\
\text { about treatment process } \\
\text { - Strategies to communicate } \\
\text { medical information to } \\
\text { children } \\
\text { - What to expect during } \\
\text { hospital stay, discharge, } \\
\text { and follow-up treatments }\end{array}$ & $\begin{array}{l}\text { - Perceived with concern } \\
\text { related to safety and } \\
\text { security } \\
\text { - Risk of miscommunication } \\
\text { and creating sentiments } \\
\text { towards healthcare staff } \\
\text { and institutions } \\
\text { - Needs to be supported by } \\
\text { a medically trained forum } \\
\text { fellow ad chat moderator } \\
\text { - If safety measures are in } \\
\text { place, forum could enable } \\
\text { creating a feeling of } \\
\text { connection and less } \\
\text { loneliness for both children } \\
\text { and parents }\end{array}$ & $\begin{array}{l}\text { - Orientation about hospital } \\
\text { facilities via virtual tours } \\
\text { and images } \\
\text { - Basic information on } \\
\text { medical treatment } \\
\text { procedures } \\
\text { - Online tutorials to educate } \\
\text { parents on how to } \\
\text { communicate with their } \\
\text { children to prepare them } \\
\text { for the hospital stay } \\
\text { - Use it as a means to } \\
\text { reduce stress and anxiety } \\
\text { in both young patients and } \\
\text { their caregivers }\end{array}$ \\
\hline
\end{tabular}

close parental observation. They also highlighted that security measures (e.g. a forum and chat moderator) should be in place, in order to ensure that children are interacting in a safe and secure environment.

Similarly, the prospect of having a platform for parents to connect with each other received mixed responses. While some parents felt comforted by the idea of knowing that they are not alone, and that it would allow them to share thoughts and experiences, other parents raised concerns with regards to the lack of medical background, the risk of providing misinformation, and the possibility that the forum would cultivate unconstructive negative sentiments towards the healthcare institution and its professionals. Thus, parents advised that an online forum would need to be supported by a medically trained forum fellow, and segmented into grouped of e.g. chronic diseases, acute admission, etc., in order to allow for appropriate and context-specific support.

(4)How to use the virtual hospital information system from a clinician's perspective (clinicians)

Healthcare professionals emphasised that the platform should be used to give orientation about the hospital facilities, displayed via virtual tours and images, and to provide some basic information on medical treatments. They also highlighted that the system should advise parents on how to effectively communicate with their child (e.g. as to what will happen during the hospital stay), in order to reduce stress levels for both young patients and their caregiver

\section{Part 2}

Findings from the workshop drawings and the workshop activities 1 and 2 were synthesized narratively, and themed into two categories: (1) Times children were most distressed/relaxed; and, (2) the ideal hospital visit (cf. Fig. 3).

\section{(1)Times they were most distressed/relaxed}

Distressing events were experienced throughout the treatment process (i.e. pre-arrival and arrival time, treatment). In particular, pain-points were expressed in relation to feeling lost, confused, where to find certain locations and who to ask. Participants emphasised the long waiting times and/or lack of guidance as to how long they had to wait until they were seen by a doctor. It was highlighted that hospital playrooms were only open at certain times and that they were mainly configured for very young patients.

In contrast, children felt most relaxed when they knew that their parents could stay with them at the hospital over-night, when nurses talked with them during waiting times, when they could watch movies, get snacks or stickers (i.e. tokens of achievements) for being good patients and when they received informative and clear explanations as to what would happen next.

\section{(2) The ideal hospital visit}

The children suggested that features of their ideal (digitalised) hospital included a general understanding of the physical layout of the hospital, i.e. an awareness of what shops are in the hospitals to get snacks from, and knowledge of who to speak to if they have questions or need further information. They also wished for a mini library, a dedicated (virtual), ageappropriate, playroom, and a mood test to complete during waiting times so that the doctor is aware of how the patient feels. Lastly, children wanted their parents and relatives to stay with them for comfort, and, if they 


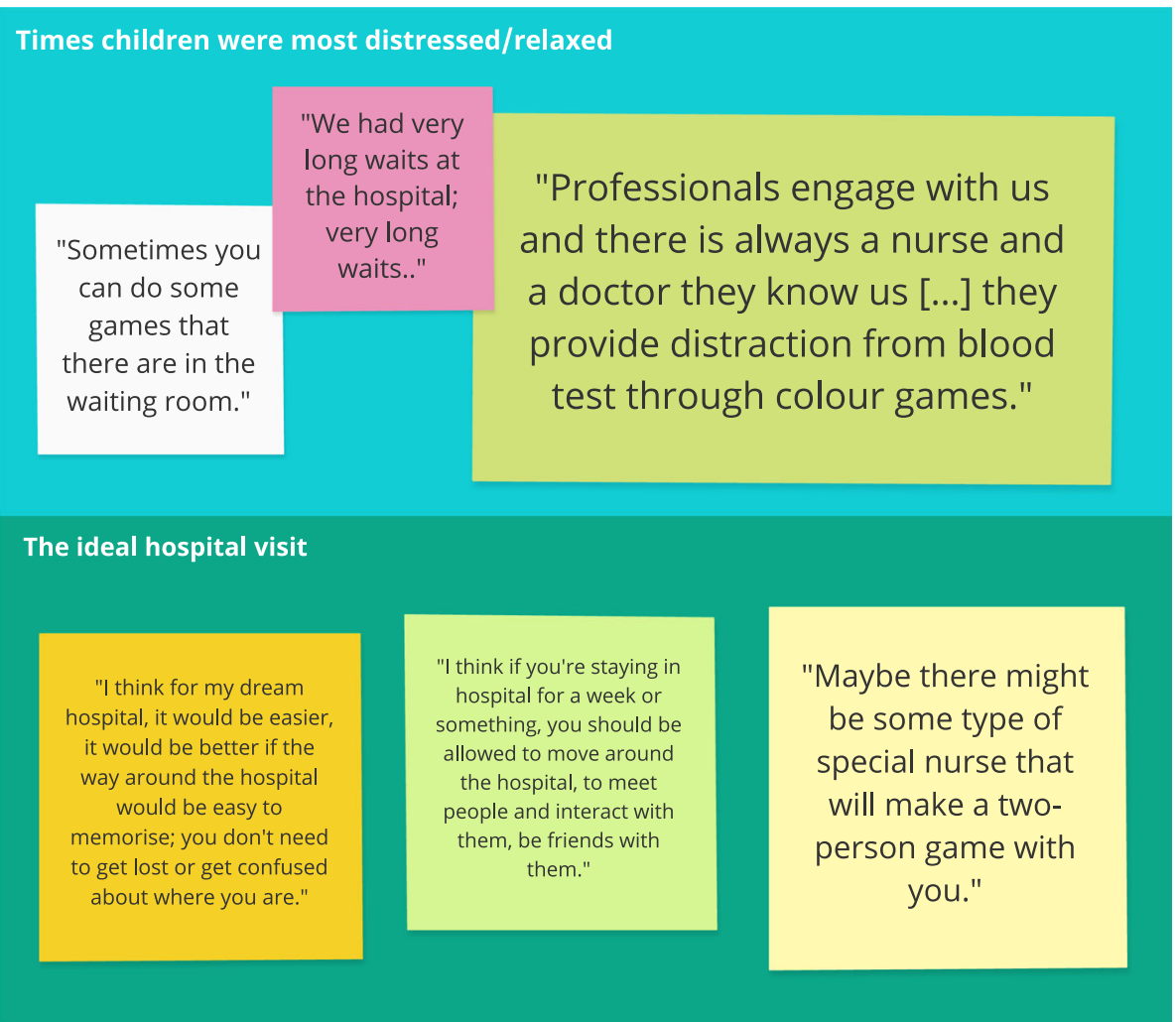

Fig. 3 Themes and exemplar quotes from the workshop (created in Miro)

required an extended admission, to have greater levels of interaction with the healthcare staff and other patients.

\section{Discussion}

This study aimed to explore the idea of co-producing a virtual hospital information system that (1) enables parents and healthcare professionals to verbally and emotionally prepare children for their hospital stay; and, (2) allows children be informed and eased into the hospital environment and treatment procedures in a playful, ageappropriate manner. Data was obtained and analysed from surveys on parents' and healthcare professionals' general perception of having a virtual information system in place specifically design for and addressed to children, and from workshop activities with children and parents.

\section{Summary of findings}

Findings from part 1 of this study showed a strong need for information for parents and children before the hospital admission. In particular, parents wished for easily digestible, non-medical explanations as to what to expect during the treatment process, accompanied by advice for parents on how to prepare their child for their hospital stay in an age-appropriate manner. They appreciated the idea of a virtual hospital information system that explains to children more about the roles and responsibilities of healthcare professionals, and, by doing so, could give them confidence and reduce anxiety and fear of the unknown. Usage of a system for children and parents to connect with each other was treated with caution and indicated that such systems need to be closely monitored and supported by medical experts.

Results from healthcare professionals highlighted the need to prepare parents and children for any policies (e.g. food and drink regimens) and schedules that they may want to consider before going to the hospital; provide an introduction to the physical environment; explain the roles and responsibilities of healthcare professionals; and suggest an estimated timeline concerning the length of waiting times to receive their treatment. They welcomed the idea of having a virtual information system that allows parents to learn how to effectively communicate with their child, and to reduce stress and anxieties.

Lastly, outcomes from the workshop reflected findings in the survey in that children were most distressed about not knowing what to expect and waiting times before treatment procedures. In contrast, children felt most relaxed when their parents could stay with them at the hospital over-night; nurses talking to them during 
waiting times; watching movies; getting snacks or stickers for being good patients (i.e. token of achievements); and receiving informative and clear explanations on their treatment.

\section{Comparison with previous literature}

Evidence suggests that patient-engaging and familycentred research leads to positive health outcomes and increased satisfaction, based on the perspectives of patients, parents, families, and health care providers [36]. A growing body of literature has also found benefits of empowering patients in decision-making, not only through the use of health information decision tools $[9,37]$, but by engaging them in exploratory and participatory healthcare intervention activities early on [38-40], aiding researchers in designing study protocols and choosing appropriate outcomes [41]. Unfortunately, research within the inpatient setting is rudimental and the evidence-base literature is highly limited, highlighting the need for more standardised, robust, and scientifically valid studies [42]. This study fills some of the gaps within the implementation of a patient engagement framework, specifically for young patients. Through UCD toolkits of engagement activities, we enabled a true "partnership" and a bidirectional exchange, where children, parents, and healthcare professionals took part in the design and decisionmaking process. Through methods such as interviews, user journeys, and cooperative inquiry, families and healthcare professionals were consulted, involved, and invited to actively collaborate [43,44], allowing our research procedure to be participative and transparent [45].

\section{Further avenues for research and practice}

This study provides numerous avenues for further research and practice:

Researchers are advised to investigate how and which method of information delivery for the hospital environment is best suited for this kind of tool. The development of a child consists of cognitive, social, physical, and emotional domains [46], and differs in progress depending on the their age and maturity development. Digital environments need to encourage active exploration and experimentation involving senses such as sounds, images, and words for adequate opportunities in providing guided interaction and learning about the hospital environment.

Researchers are, furthermore, encouraged to conduct design studies in consideration of cultural differences and digital literacy, such as differences in colour meaning and gestures, as well as user interfaces to assist attention and comprehension [47]. Overall, an understanding of what user interface and design features (e.g. colours, fonts, layout, navigation, level of interaction) resonates with young patients and their parents will clarify the most effective way of preparing them for a potential hospital admission and treatment.

Once fully developed and implemented, studies should be designed to understand the impact of such designed information system compared to other systems, as well as standard care alone. These may include patients' and carers' hospital experience satisfaction, changes in anxiety and post-operative mal-adaptive behaviour, or healthcare outcomes including recovery rate indicated by e.g. the length of hospital stay. They should also explore how the system could be used to connect patients and parents, and how to actively involve healthcare professionals during the that process.

Safety and privacy concerns for application design in digital healthcare need to be tackled [48]. Medical information technology applications that allow for the possibility of data sharing have concrete implications on the design of such application. Thus, handling of sensitive data need to go through anonymization process prior to sharing to eliminate legislative obligations and constraints.

Lastly, future work is necessary in simulating similar, repeated events at a larger scale to encourage open discourses and discussions on patient information systems designed specifically for children. These discussion could be on how virtual information systems should be used to aid with the admission and treatment process; other discussion may tackle how such information technology enhance health literacy and patient safety. Health literacy enables patients to process, understand, and make sense of health information in a way that can significantly impact their health decision and behaviours [8]. By being able to create a critical thinking approach on how patients' own behaviours impact their health, information technologies have the potential to generate a positive and stronger long-term impact, which, for continuous treatment procedures or hospital admissions appears a valuable stream of research.

\section{Limitations}

For the workshop activity in study 2, participants were paid to take part and the sample size was relatively small. However, while this increased the risk of a sample selection bias and limited feedback [41] it allowed for enhanced interaction and participation, which was the main aim of the workshop. Future initiatives are therefore encouraged to aim for patient involvement activities at larger scales, or through iterative design workshops, that encourage increased attendance and contributions related to improving healthcare service and delivery.

Information regarding the children's presentation, investigation or treatment at hospital was incomplete, thus we cannot ascertain whether our sample group was representative of the wider population of child patients in this regard. Recent studies have shown that information technology/anxiety reducing interventions are designed 
most commonly for young patients in relation to surgery with/without general anaesthesia [17-19, 49-53], burns wound treatments [54-56], and intravenous cannulation [57]. Knowing what condition and medical service the information technology will support will be crucial to help children assist in the admission and treatment process, not only for specific conditions and healthcare settings, but also when it comes to healthcare services compared to other countries. Treatment specific and localised technologies will allow for a more accurate reflection of the patient's experiences and care.

Findings are limited in terms of its generalisation [58]. While we believe that results can be transferred to different settings within the hospital admission and treatment processes, ranging from general health check-ups to elective surgeries, where hospital information on the infrastructure and roles and responsibilities of healthcare professionals apply irrespective of the type of health care delivered, future studies are encouraged to gather more in-depth user requirements [59]. These should be context and user specific, and further inform the design and development of such information technology.

\section{Conclusion}

This study aims to co-produce and design a virtual information system specifically designed with and for young patients and their caregivers. Results suggest that this system needs to provide information related to roles and responsibilities of healthcare staff, and basic medical information regarding patients' treatment, in order to increase their confidence and reduce their anxiety and fear of the hospital visit. Future studies are encouraged to further investigate how to improve patients' experience, quality and safety of healthcare delivery, through a virtual information system for younger patients with large-scale potentials.

\section{Abbreviation}

UCD: User-Centred Design

\begin{abstract}
Acknowledgements
We thank the National Institute for Health Research (NIHR) Imperial Patient Safety Translation Research Centre (PSTRC) and the Imperial College NHS Trust Biomedical Research Centre (BRC) for their support of this research. We thank the Imperial College Outreach team for their assistance in organising the workshop. We also wish to thank all participants and helpers, including Suraj Gandhi, Sophie Howard, Azita Ahmadi, and Daniela Rodrigues, for their contributions during the workshop and towards this paper, and UX Designer Tom Stables, for his input throughout the research and design process.
\end{abstract}

\section{Authors' contributions}

$L A, K H B, C B$ and $A D$ conceptualised this research. $L A$ and $K B H$ collected and analysed the data. The manuscript was written by LA with contributions from all authors. All authors have read and approved the manuscript.

\section{Funding}

This work is supported by the National Institute for Health Research (NIHR: P69339; awarded to AD; https://www.nihr.ac.uk) Patient Safety Translation Research Centre, and the Imperial College NHS Trust Biomedical Research Centre, early career research fund (BRC:PS3526; awarded to LA; https:// imperialbrc.nihr.ac.uk), UK. The views of the authors do not necessarily reflect those of the NHS, NIHR or the Department of Health. The funder had no role in study design, data collection and analysis, decision to publish, or preparation of the manuscript.

\section{Availability of data and materials}

We are unable to share data due to sensitive patient information. This is line with the ethics committee approval (Imperial College Research Ethics Committee) and it was made clear on consent forms that data would not be shared to anyone other than the researcher and immediate research team. Please contact Dr Ruth Nicholson, Imperial College London, (r. nicholson@imperial.ac.uk) to field future data request

\section{Ethics approval and consent to participate}

The study was reviewed and ethically approved by the Joint Research Compliance Office (JRCO; 19IC5541), Imperial College London, UK. Written and fully informed consent was obtained from all participants, including parents/guardians of the minors as well as the children themselves.

\section{Consent for publication}

Not applicable

\section{Competing interests}

We declare no conflict(s) of interest associated with this research.

Received: 6 April 2020 Accepted: 28 September 2020

Published online: 08 October 2020

\section{References}

1. Lerwick JL. Minimizing pediatric healthcare-induced anxiety and trauma. World J Clin Pediatr. 2016;5(2):143-50.

2. Wray J, Lee K, Dearmun N, Franck L. Parental anxiety and stress during children's hospitalisation: the StayClose study. J Child Health Care. 2011; 15(3):163-74.

3. Piira T, Sugiura T, Champion GD, Donnelly N, Cole ASJ. The role of parental presence in the context of children's medical procedures: a systematic review. Child. 2005;31(2):233-43.

4. De Mula-Fuentes B, Quintana M, Rimbau J, Martínez-Mejías A, Úriz M, RiveraPérez C, et al. Anxiety, hospital fears and conduct and behavioral alterations during pediatric hospitalization. Actas Esp Psiquiatr. 2018:46(2):42-50.

5. Caes L, Goubert L, Devos P, Verlooy J, Benoit Y, Vervoort T. The Relationship Between Parental Catastrophizing About Child Pain and Distress in Response to Medical Procedures in the Context of Childhood Cancer Treatment: A Longitudinal Analysis. Journal of Pediatric Psychology. 2014; 39(7):677-86

6. Li WHC, Chung JOK, Ho KY, Kwok BMC. Play interventions to reduce anxiety and negative emotions in hospitalized children. BMC Pediatr. 2016;16:36.

7. Wong CL, Lui MMW, Choi KC. Effects of immersive virtual reality intervention on pain and anxiety among pediatric patients undergoing venipuncture: a study protocol for a randomized controlled trial. Trials. 2019; 20(1):369.

8. Cusack L, Del Mar CB, Chalmers I, Gibson E, Hoffmann TC. Educational interventions to improve people's understanding of key concepts in assessing the effects of health interventions: a systematic review. Syst Rev. 2018;7(1):68.

9. Cené CW, Johnson BH, Wells N, Baker B, Davis R, Turchi R. A Narrative Review of Patient and Family Engagement: The "Foundation" of the Medical "Home." Med Care. 2016;54(7):697-705.

10. Costa Fernandes $S$, Arriaga P. The effects of clown intervention on worries and emotional responses in children undergoing surgery. Journal of Health Psychology. 2010;15(3):405-15.

11. Wong CL, Ip WY, Kwok BMC, Choi KC, Ng BKW, Chan CWH. Effects of therapeutic play on children undergoing cast-removal procedures: a randomised controlled trial. BMJ Open. 2018:8(7):e021071.

12. Dionigi A, Sangiorgi D, Flangini R. Clown intervention to reduce preoperative anxiety in children and parents: A randomized controlled trial. J Health Psychol. 2013;19(3):369-80.

13. Li HCW, Lopez V, Lee TLI. Psychoeducational preparation of children for surgery: The importance of parental involvement. Patient Education Counseling. 2007;65(1):34-41

14. Gleason MM. Early Childhood Health Interventions in the Primary Care Setting Promote Developmental Outcomes. J Pediatrics. 2018;199:13-5. 
15. Patel A, Schieble T, Davidson M, Tran MCJ, Schoenberg C, Delphin E, et al. Distraction with a hand-held video game reduces pediatric preoperative anxiety. Pediatric Anesthesia. 2006;16(10):1019-27.

16. Barello S, Triberti S, Graffigna G, Libreri C, Serino S, Hibbard J, et al. eHealth for Patient Engagement: A Systematic Review. Front Psychol. 2015;6:2013.

17. Batuman A, Gulec E, Turktan M, Gunes Y, Ozcengiz D. Preoperative informational video reduces preoperative anxiety and postoperative negative behavioral changes in children. Minerva Anestesiol. 2016;82(5):534-42.

18. Dehghan $F$, Jalali $R$, Bashiri $H$. The effect of virtual reality technology on preoperative anxiety in children: a Solomon four-group randomized clinical trial. Perioperative Medicine. 2019;8(1):5.

19. Eijlers R, Dierckx B, Staals LM, Berghmans JM, van der Schroeff MP, Strabbing EM, et al. Virtual reality exposure before elective day care surgery to reduce anxiety and pain in children: A randomised controlled trial. Eur J Anaesthesiol (EJA). 2019;36(10):728-37.

20. Agarwal R, Gao G, DesRoches C, Jha KA. Research Commentary--The Digital Transformation of Healthcare: Current Status and the Road Ahead. Info Sys Research. 2010;21(4):796-809.

21. Chamberlain S, Sharp H, Maiden N, editors. Towards a framework for integrating agile development and user-centred design. Extreme programming and agile processes in software engineering. Berlin, Heidelberg: Springer; 2006.

22. Johnson CM, Johnson TR, Zhang J. A user-centered framework for redesigning health care interfaces. Journal of Biomedical Informatics. 2005 38(1):75-87.

23. Maguire M, Bevan N. User Requirements Analysis. In: Hammond J, Gross T, Wesson J, editors. Usability: Gaining a Competitive Edge. Boston: Springer US; 2002. p. 133-48.

24. Guest G, Bunce A, Johnson L. How Many Interviews Are Enough? An Experiment with Data Saturation and Variability. Field Methods. 2006;18(1): 59-82.

25. Morse JM. The Significance of Saturation. Qualitative Health Research. 1995; 5(2):147-9.

26. Andersen MH, Khalid MS, Brooks El, editors. Considerations and methods for usability testing with children. Interactivity, game creation, design, learning, and innovation. Cham: Springer International Publishing; 2017.

27. McCarthy S, O'Raghallaigh P, Woodworth S, Lim YL, Kenny LC, Adam F. An integrated patient journey mapping tool for embedding quality in healthcare service reform. J Decision Syst. 2016;25(sup1):354-68.

28. Trebble TM, Hansi N, Hydes T, Smith MA, Baker M. Process mapping the patient journey: an introduction. BMJ. 2010;341:c4078.

29. Abbas $\mathrm{R}$, Tootell H, Freeman M, Ellmers G. Engaging young children as application design partners: a stakeholder-inclusive methodological approach. IEEE Technol Society Magazine. 2018;37(3):38-47.

30. Guha ML, Druin A, Chipman G, Fails JA, Simms S, Farber A. Working with young children as technology design partners. Commun ACM. 2005;48(1): 39-42.

31. Guha ML, Druin A, Fails JA. Cooperative Inquiry revisited: Reflections of the past and guidelines for the future of intergenerational co-design. Int J Child-Computer Interaction. 2013;1(1):14-23.

32. Braun V, Clarke V. Using thematic analysis in psychology. Qualitative Res Psychol. 2006;3(2):77-101.

33. Darbyshire P, Macdougall C, Schiller W. Multiple methods in qualitative research with children: more insight or just mor? Qual Res. 2005;5:417-36.

34. Guillemin M. Understanding illness: using drawings as a research method. Qual Health Res. 2004;14(2):272-89.

35. Bird CM, How I. Stopped dreading and learned to love transcription. Qual Inq. 2005;11(2):226-48.

36. Cypress BS. Family Presence on Rounds: A Systematic Review of Literature. Dimens Crit Care Nurs. 2012;31(1):53-64.

37. Adams WG, Phillips BD, Bacic JD, Walsh KE, Shanahan CW, Paasche-Orlow MK. Automated conversation system before pediatric primary care visits: a randomized trial. Pediatrics. 2014;134(3):e691.

38. Clayman ML, Bylund CL, Chewning B, Makoul G. The impact of patient participation in health decisions within medical encounters: a systematic review. Med Dec Making. 2015;36(4):427-52.

39. Goodridge D, Henry C, Watson E, McDonald M, New L, Harrison EL, et al. Structured approaches to promote patient and family engagement in treatment in acute care hospital settings: protocol for a systematic scoping review. Syst Rev. 2018;7(1):35
40. Likumahuwa-Ackman S, Angier H, Sumic A, Harding RL, Cottrell EK, Cohen DJ, et al. IMPACCT Kids' Care: a real-world example of stakeholder involvement in comparative effectiveness research. J Comp Eff Res. 2015; 4(4):351-7.

41. Domecq JP, Prutsky G, Elraiyah T, Wang Z, Nabhan M, Shippee N, et al. Patient engagement in research: a systematic review. BMC Health Serv Res. 2014;14(1):89

42. Prey JE, Woollen J, Wilcox L, Sackeim AD, Hripcsak G, Bakken S, et al. Patient engagement in the inpatient setting: a systematic review. J Am Med Informatics Assoc. 2013;21(4):742-50.

43. Coulter A, Ellins J. Effectiveness of strategies for informing, educating, and involving patients. BMJ. 2007;335(7609):24.

44. Kovacs Burns K, Bellows M, Eigenseher C, Gallivan J. 'Practical' resources to support patient and family engagement in healthcare decisions: a scoping review. BMC Health Serv Res. 2014;14(1):175.

45. Anton S. Involving the public in NHS service planning. J Health Organization Manag. 2007;21(4/5):470-83.

46. Cooper LZ. Developmentally appropriate digital environments for young children. Library Trends. 2005;54(2):286-302.

47. Punchoojit L, Hongwarittorrn N. Usability studies on mobile user interface design patterns: a systematic literature review. Adv Human-Computer Interaction. 2017:2017:1-22.

48. Volk M, Sterle J, Sedlar U. Safety and privacy considerations for mobile application design in digital healthcare. Int J Distributed Sensor Networks. 2015;11(10):549420.

49. Ryu J-H, Oh A-Y, Yoo H-J, Kim J-H, Park J-W, Han S-H. The effect of an immersive virtual reality tour of the operating theater on emergence delirium in children undergoing general anesthesia: A randomized controlled trial. Pediatric Anesthesia. 2019;29(1):98-105.

50. Ryu J-H, Park J-W, Nahm SF, Jeon Y-T, Oh A-Y, Lee JH, et al. The effect of gamification through a virtual reality on preoperative anxiety in pediatric patients undergoing general anesthesia: a prospective, randomized, and controlled Trial. J Clin Med. 2018;7(9):284

51. Ryu JH, Park SJ, Park JW, Kim JW, Yoo HJ, Kim TW, et al. Randomized clinical trial of immersive virtual reality tour of the operating theatre in children before anaesthesia. Brit J Surg. 2017;104(12):1628-33.

52. Park J, Nahm FS, Kim J, Jeon Y, Ryu J, Han S. The Effect of Mirroring Display of Virtual Reality Tour of the Operating Theatre on Preoperative Anxiety: A Randomized Controlled Trial. IEEE J Biomed Health Informatics. 2019;23(6):2655-60.

53. Fernandes S, Arriaga P, Esteves F. Using an educational multimedia application to prepare children for outpatient surgeries. Health Commun. 2015;30(12):1190-200.

54. Miller K, Rodger S, Kipping B, Kimble RM. A novel technology approach to pain management in children with burns: A prospective randomized controlled trial. Burns. 2011;37(3):395-405.

55. Brown NJ, Kimble RM, Rodger S, Ware RS, Cuttle L. Play and heal: Randomized controlled trial of Ditto ${ }^{\text {TM }}$ intervention efficacy on improving re-epithelialization in pediatric burns. Burns. 2014;40(2):204-13.

56. Miller K, Rodger S, Bucolo S, Greer R, Kimble RM. Multi-modal distraction. Using technology to combat pain in young children with burn injuries. Burns. 2010;36(5):647-58

57. Miller K, Tan X, Hobson AD, Khan A, Ziviani J, O'Brien E, et al. A prospective randomized controlled trial of nonpharmacological pain management during intravenous cannulation in a pediatric emergency department. Pediatr Emerg Care. 2016;32(7):444-51.

58. Schreier M. Sampling and generalization. 2018 2020/04/05. In: The SAGE Handbook of Qualitative Data Collection. London: SAGE Publications Ltd; [84-97]. Available from: https://sk.sagepub.com/reference/the-sagehandbook-of-qualitative-data-collection.

59. Lucassen G, Dalpiaz F, Werf JMEMvd, Brinkkemper S, editors. Forging highquality user stories: towards a discipline for agile requirements. IEEE 23rd International Requirements Engineering Conference; 2015.

\section{Publisher's Note}

Springer Nature remains neutral with regard to jurisdictional claims in published maps and institutional affiliations. 